\title{
Corrigendum
}

\section{Inhibition of neogenin fosters resolution of inflammation and tissue regeneration}

Martin Schlegel, Andreas Körner, Torsten Kaussen, Urs Knausberg, Carmen Gerber, Georg Hansmann, Hulda Soffia Jónasdóttir, Martin Giera, and Valbona Mirakaj

Original citation: J Clin Invest. 2018;128(10):4711-4726. https://doi.org/10.1172/JCI96259.

Citation for this corrigendum: J Clin Invest. 2019;129(5):2165. https://doi.org/10.1172/JCI128681.

During the preparation of this manuscript, the colors used to indicate WT and $\mathrm{Neol}^{-/-}$mice after ZyA injection in Figures 2E, 2F, 8C, and 9A were transposed. The correct figure parts are below.

The authors regret the errors.

\section{Figure 2}
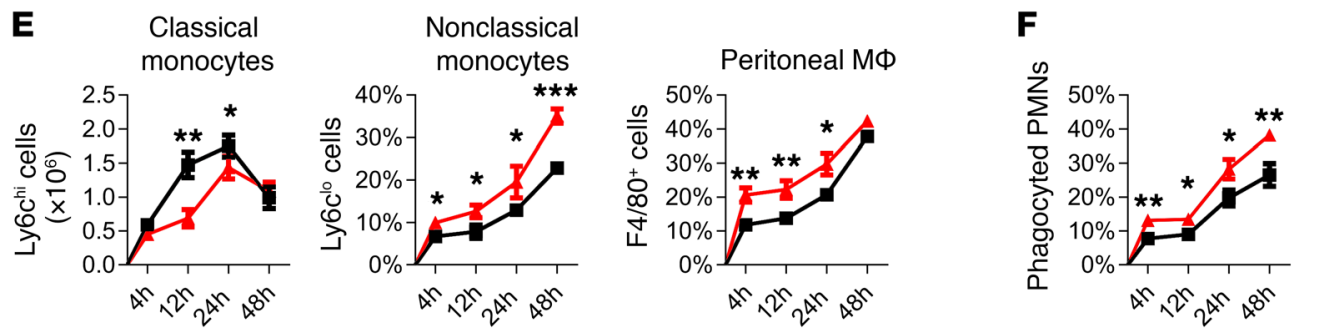

\section{Figure 8}
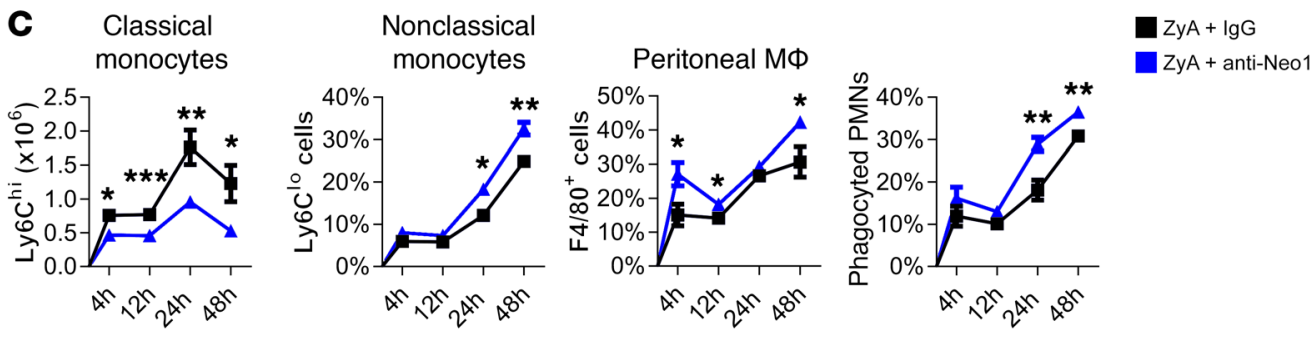

Figure 9

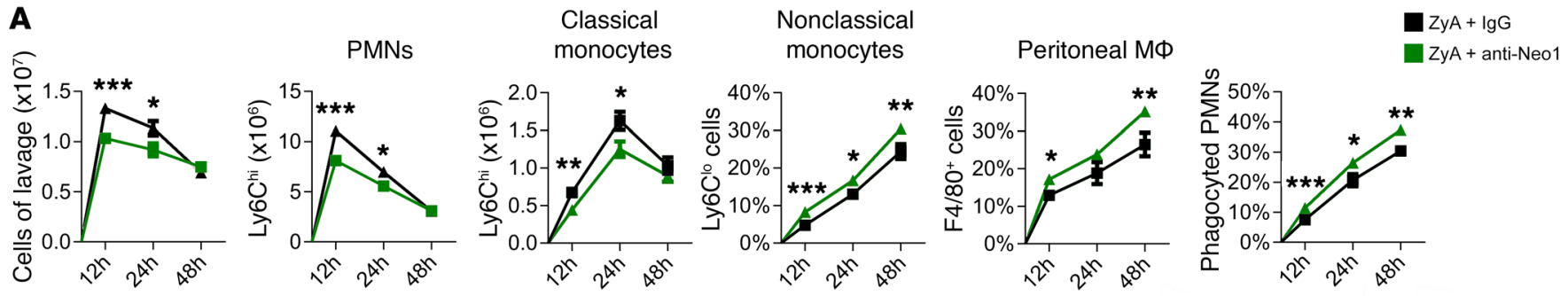

